\title{
Heartbeat: health literacy for improving cardiac outcomes
}

The potential impact of patient education on improving outcomes in patients with cardiovascular disease (CVD) has received little attention. In a randomised clinical trial, McIntyre and colleagues ${ }^{1}$ found that waiting room video-based education about CVD risk reduction resulted in more patients being motivated to implement heart healthy behaviours $(29.6 \%$ vs $18.7 \%$, relative risk $1.63,95 \%$ CI 1.04 to 2.55 ) and higher levels of satisfaction with the clinic visit. Participants who were also randomised to receive education about cardio-pulmonary resuscitation (CPR) reported greater confidence in performing CPR. Overall, at baseline $16 \%$ of patients reported optimal CVD risk factors which increased to $25 \%$ at 30 days but there was no difference in improvement between the intervention group and usual care (figure 1).

In an editorial, White ${ }^{2}$ comments that 'Health literacy is an underused resource for improving cardiac outcomes with patients being better able to understand their disease, understand modifications in their lifestyles required for prevention such as nutrition and exercise and understand the need for medications that may improve adherence. Patients may therefore be better able to maintain their own health and well-being. Waiting room computer tablets have the potential to improve outcomes.' Clearly, additional research is needed on the optimal educational materials and presentation formats to improve cardiovascular outcomes, hopefully with close collaboration between patients and healthcare providers.

Also in this issue of Heart, Imberti and colleagues ${ }^{3}$ present data from a systematic review and meta-analysis to support catheter ablation (CA) as firstline treatment in patients with paroxysmal atrial fibrillation (AF). In 1212 patients with paroxysmal AF combined from six studies, those treated with CA had a $36 \%$ relative risk reduction for recurrent arrhythmias compared with

Division of Cardiology, University of Washington, Seattle, Washington, USA

Correspondence to Professor Catherine M Otto, Division of Cardiology, University of Washington, Seattle, WA 98195, USA; cmotto@uw.edu
(1) While You're Waiting: A Randomised Clinical Trial After clinic, participants who had received the program were Patients with cardiovascular disease (CVD) can spend more time in clinic waiting rooms than with their doctor. We aimed to assess whether waiting time could be used to deliver education on CVD risk factors and cardio-pulmonary resuscitation (CPR).

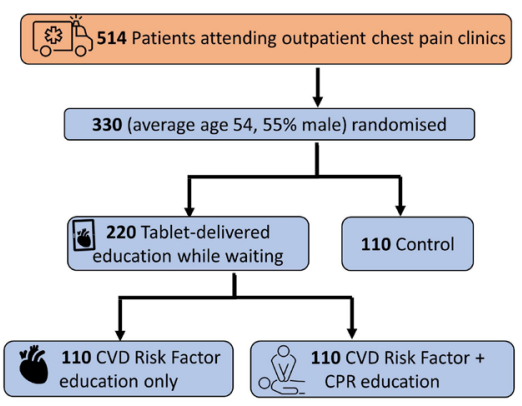

Figure 1 Informational graphic summary of the While You're Waiting study.

those treated with medications, with symptomatic recurrent arrhythmias in $20 \%$ vs $37 \%$ and lower rates of healthcare utilisation (figure 2).

Blaauw, Mulder and Rienstra ${ }^{4}$ concur with the conclusion that CA is more effective than anti-arrhythmic medication for reducing recurrent $\mathrm{AF}$ but urge caution in widespread adoption of this approach because 'questions remain regarding timing of CA, selection of patients, quality of life outcomes, balancing procedural complications and AAD side effects, and management.' instituting risk factor management as background therapy.' They urge 'Shared decision-making focusing on individualised timing and balancing benefits-risks is the preferred approach to assess firstline treatment with CA. As CA is rapidly evolving, with novel single-shot devices and promising energy sources (eg, pulsed field ablation), it is foreseen that CA keeps moving towards the frontline of AF

In an elegant study using cardiac MRI combined with statistical machine

\section{A}

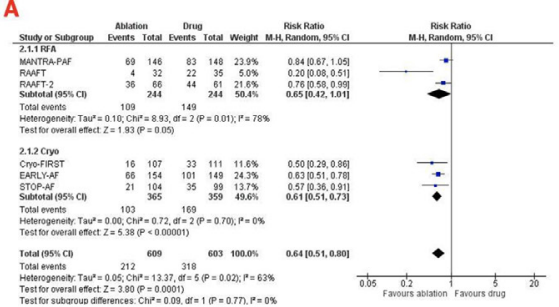

B
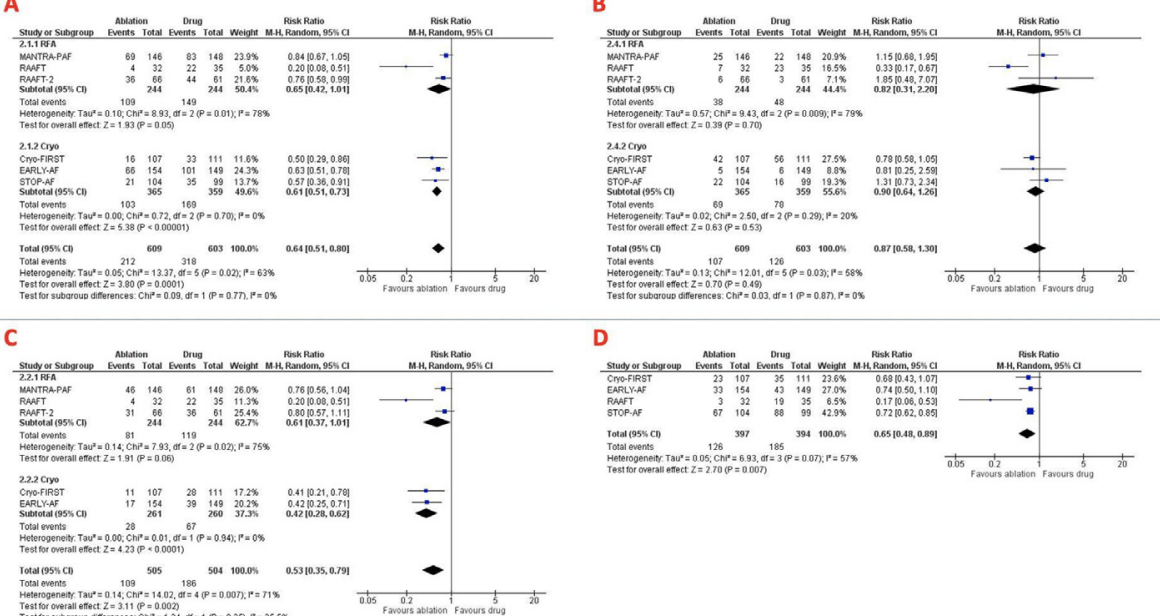

Figure 2 Forest plots showing the comparative efficacy and safety of catheter ablation vs antiarrhythmic drugs as first-line treatment of paroxysmal atrial fibrillation. (A) Risk of atrial arrhythmia recurrence. (B) Risk of serious adverse events. (C) Risk of symptomatic arrhythmia recurrence. (D) Risk of healthcare resources use. $\mathrm{Cl}$, confidence interval; Cryo, cryoballoon ablation; $\mathrm{M}-\mathrm{H}$, Mantel-Haenszel; RFA, radiofrequency ablation; RR, risk ratio. 

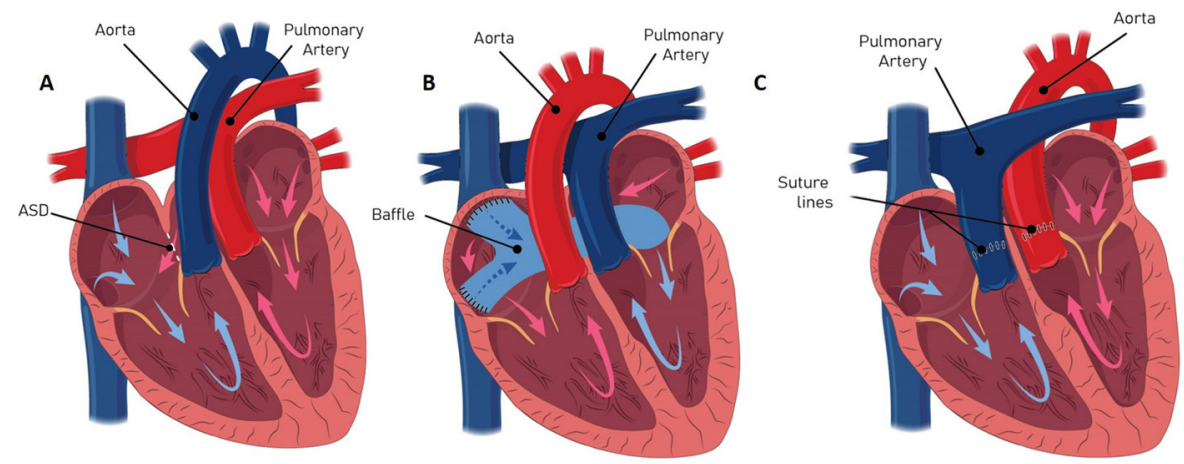

Figure 3 Schematic of (A) d-transposition of the great arteries, (B) d-TGA following ASR and (C) D-TGA following ASO. ASO, arterial switch operation; ASR, atrial switch repair. learning methods, Schuwerk and colleagues ${ }^{5}$ demonstrate overall normal biventricular and biatrial function in patients with an arterial switch operation for transposition of the great arteries (TGA). Only right ventricular longitudinal strain and left atrial function were impaired at a median of 16 years after surgery.

Going forward, Ostenfeld and Carlsson ${ }^{6}$ suggest that 'Remaining questions in this patient group are if the ventricular and atrial function parameters have any prognostic information when all four chambers are examined. Furthermore, assessment of fibrosis and perfusion related to heart function in patients with TGA and arterial switch operation would be of interest in the future.' A review article by Gaur and colleague $^{7}$ discusses overall management consideration in adults with surgically modified TGA, including both those with an atrial and those with an arterial switch procedure (figure 3).

The Education in Heart article ${ }^{8}$ in this issue addresses management of ventricular tachycardia storm including diagnostic criteria, initial management and a multidisciplinary team approach to long-term care.

The Cardiology in Focus article ${ }^{9}$ in this issue provides information about the need for and training of cardiologists in global health. As Akhter and colleagues note: 'In the ecosystem of global cardiovascular healthcare, cardiologists are a part of a multidisciplinary, multisector response in which global cooperation can support better health outcomes.' (figure 4).

Funding The authors have not declared a specific grant for this research from any funding agency in the public, commercial or not-for-profit sectors.

Competing interests None declared.

Patient and public involvement Patients and/or the public were not involved in the design, or conduct, or reporting, or dissemination plans of this research.

Patient consent for publication Not applicable.

Provenance and peer review Commissioned; internally peer reviewed.

(c) Author(s) (or their employer(s)) 2021. No commercial re-use. See rights and permissions. Published by BMJ.

\section{A) Check for updates}

To cite Otto CM. Heart 2021;107:1603-1604.

Heart 2021;107:1603-1604.

doi:10.1136/heartjnl-2021-320311

ORCID iD

Catherine M Otto http://orcid.org/0000-0002-05279392

\section{REFERENCES}

1 McIntyre $D$, Thiagalingam A, Klimis $\mathrm{H}$, et al. Education on cardiac risk and CPR in cardiology clinic waiting rooms: a randomised clinical trial. Heart 2021;107:1637-43.

2 White HD. Waiting room computer tablets to improve health literacy and cardiovascular outcomes. Heart 2021;107:1607-8.

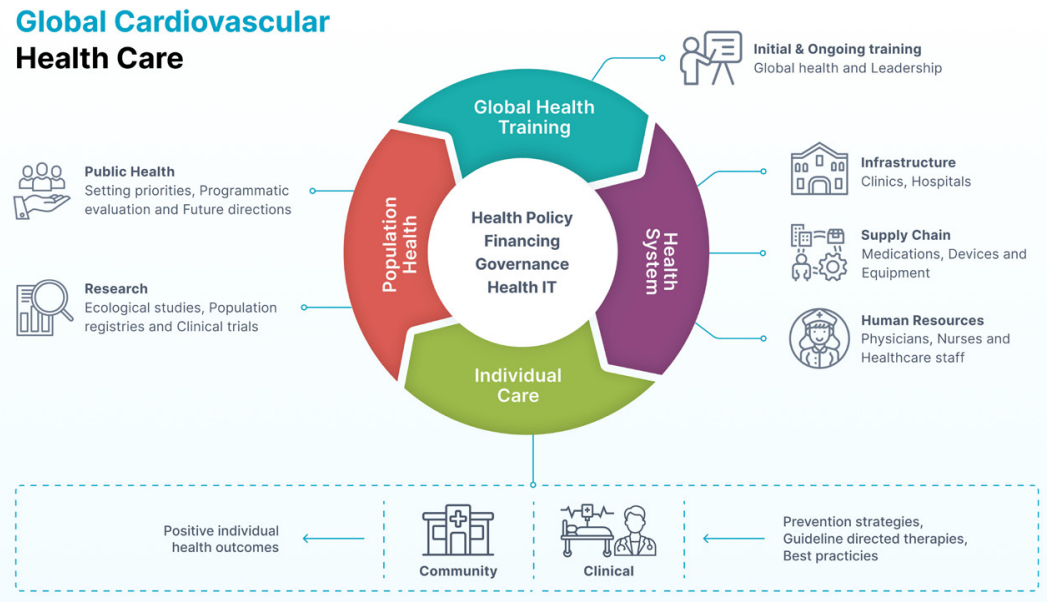

Figure 4 Global cardiovascular healthcare. IT, information technology. 